\title{
Complex of technical solutions for protection and selective signaling of single-phase earth faults in 6-10 kV distribution cable networks
}

\author{
Vladimir Shuin ${ }^{1, *}$, Tatiana Shadrikova ${ }^{1}$, Olga Dobryagina $^{1}$, and Elena Shagurina ${ }^{1}$ \\ ${ }^{1}$ Ivanovo State Power Engineering University named after V.I. Lenin, 153003, Ivanovo, st. Rabfakovskaya, 34, Russia
}

\begin{abstract}
Single-phase earth faults are the predominant type of damage in distribution $6-10 \mathrm{kV}$ cable networks, and are often the root cause of power failures to consumers, accompanied by significant economic damage. Therefore, reliability for about $50 \%$ of consumers of industrial and urban power supply systems depends on the technical perfection of protection against earth faults. The currently used approach to the design of protection and signaling of earth faults, based on the application of the existing concept of selectivity of considered protection, does not always ensure the achievement of the main goal - increasing the reliability of power supply to consumers. To improve the reliability of power supply, new technical solutions are needed that provide not only selective detection of the damaged connection for all types of single-phase earth faults, but also the recognition of the most dangerous for the network and the protected connection faults types for automatic selection the most effective protection action (signal or shutdown). Within the framework of the existing approach, the design of protection against earth faults with the specified properties is possible only on the basis different methods of its implementation in networks with different neutral grounding modes, which is associated with the complication of protection circuit, its design and exploitation. A new approach has been proposed that provides universal technical solutions for protection and signaling of earth faults for $6-10 \mathrm{kV}$ cable networks with various neutral grounding modes. To implement the proposed approach, universal adaptive current protection and universal admittance protection based on the control of the capacitance of zero sequence loop of the protected connection have been developed.
\end{abstract}

\section{Introduction}

About $50 \%$ of electricity in Russia is distributed to consumers of industrial and urban power supply systems through 6-10 kV cable networks. Accidents in 6-10 kV cable networks account for about $70 \%$ of all power supply failures to consumers, and the root cause of most of the emergency shutdowns of cable lines and other elements (for example, high-voltage electric motors) is single-phase earth faults, accounting for $75-90 \%$ of the total number of electrical faults in the indicated networks $[1$, etc.]. Therefore, the reliability of power supply to consumers depends on the speed of identifying and disconnecting the damaged element, i.e. technical excellence (selectivity and stability of functioning) protection against earth faults.

When developing protection devices against singlephase earth faults with high selectivity and stability of operation, difficulties arise, primarily due to the use of various neutral grounding modes in $6-10 \mathrm{kV}$ cable networks and a variety of types of earth faults taken into account when performing protection against this type of damage (stable faults - metal and through transient resistance, alternating arc earth faults, short-term self- eliminating insulation breakdowns). Neutral grounding modes determine the nature of electromagnetic processes in transient and steady-state earth fault modes and, therefore, methods of performing selective protection against this type of damage.

So for protection against single-phase earth faults in 6$10 \mathrm{kV}$ cable networks with isolated neutral or with highresistance neutral grounding, simple and reliable overcurrent zero sequence protection, based on the use of components of fundamental frequency $(50 \mathrm{~Hz})$ of current $3 I_{0}[2,3$, etc. $]$ is most widely used, in compensated networks - overcurrent protection based on the use of higher harmonics of the zero sequence current of protected connection [6, etc.].

The main factor limiting the selectivity and sensitivity of overcurrent zero sequence protections in $6-10 \mathrm{kV}$ cable networks with isolated neutral is the transient current inrush that occur during intermittent arcing earth faults [1]. According to the conditions of selectivity of nonoperation at external arc intermittent earth faults and minimum sensitivity at internal stable faults, the use of overcurrent zero sequence protection is possible only on connections whose own capacitive current $I_{\mathrm{c} \text { own }}$ does not exceed $15-20 \%$ of the total network capacitive current

\footnotetext{
* Corresponding author: rza@rza.ispu.ru
} 
$I_{\mathrm{C} \Sigma}[2]$. The selectivity and sensitivity of overcurrent protection based on higher harmonics are limited primarily by fluctuations in higher harmonics level in the stable earth fault current in various operating modes of the protected compensated $6-10 \mathrm{kV}$ cable network. Practically non-operation at external and the required sensitivity at internal stable earth faults of overcurrent protection based on higher harmonics can be provided only at connections with own capacitive current $I_{\mathrm{c} \text { own }} * 0.07-0.1$ [5], which significantly limits the scope of this protection.

In cases where, according to the conditions of selectivity and sensitivity, the use of overcurrent zero sequence protections is impossible, in networks with isolated neutral and with high-resistance neutral grounding, directional zero sequence current protection is used $[2,6$, etc.]. The main disadvantage of some versions of directional current protection is the possibility of operation failures due to violations of the phase relationships between $3 u_{0}$ and $3 i_{0}$ during earth faults through an intermittent arc [2,7], as well as due to possible in real operating conditions errors in the polarity of the protection connection to the secondary winding cable current zero sequence transformer. In compensated cable networks, directional protection based on higher harmonics has not been used.

In European countries, in medium voltage distribution networks operating with an isolated neutral, along with overcurrent and directional current zero sequence protection, non-directional and directional admittance protection against earth faults, based on the control of the admittance of the zero-sequence loop of the protected connection or its orthogonal components at the fundamental frequency, are also widely used [8].

In compensated and uncompensated $6-10 \mathrm{kV}$ cable networks, protections based on the use of electrical quantities of the transient process can also be used [2, 9, etc.]. The advantage of this protection is the possibility of selective fixation of short-term self-eliminating breakdowns, which are typical primarily for compensated cable networks, as well as high selectivity for faults through an intermittent arc. The main disadvantage limiting the widespread use of this type of protection is their lack of operation continuity with stable faults, which is necessary when searching for a damaged section of a cable line using operational switching in network.

From the above it follows that in order to obtain a comprehensive solution to the problem of selective protection against earth faults in medium voltage cable networks with different neutral grounding modes, the developers of modern microprocessor terminals as part of relay protection and automation functions are forced to provide several functions of protection against earth faults on various principles designed for use in various neutral grounding modes or action in various types of single-phase earth faults. This leads to the complexity of the earth fault protection, its design and operation.

A simpler and more universal solution allows one to obtain protections currently being developed both in Russia and in some other countries, based on the use of electrical quantities of both the transient process and steady-state earth fault [for example, 12]. For the operation of such protections in uncompensated networks, the sum of the component of the fundamental frequency and higher harmonic components of zero sequence current $3 i_{0}$ and voltage $3 u_{0}$ are used, in compensated networks - the sum of only higher harmonic components $3 i_{0}$ and $3 u_{0}$. This principle of implementation of protection against earth faults is also called multifrequency [10].

On the basis of the multifrequency principle, Ivanovo State Power Engineering University together with NPP EKRA for compensated and uncompensated 6-10 kV networks are developing universal adaptive current protection [11] and universal admittance protection based on the control of not conductivity, but directly the capacitance of the zero sequence loop of the protected connection [12]. The method of action and principles of implementation of these protections are discussed below.

\section{Universal multifrequency adaptive overcurrent protection}

In the steady-state and transient earth fault mode, for instantaneous values of zero-sequence currents of undamaged $3 i_{0 \text { und }}(t)$ and damaged $3 i_{0 \text { dam }}(t)$ connections of $6-10 \mathrm{kV}$ cable networks with isolated neutral in the frequency range up to $1.5-2 \mathrm{kHz}$, the following relations are valid [13]:

$$
\begin{gathered}
3 i_{0 \text { und }}(t) \approx 3 C_{0 \text { own }} u_{0}^{\prime}(t) \\
3 i_{0 \text { dam }}(t) \approx-3\left(C_{0 \Sigma}-C_{0 \text { own }}\right) u_{0}^{\prime}(t)
\end{gathered}
$$

where $3 C_{0 \text { own }}$ - own phase capacitance to ground of the protected line; $C_{0 \Sigma}$ - total capacity of the network phases to earth; $u_{0}^{\prime}(t)$ - instantaneous value of zero sequence voltage derivative.

In compensated networks, relations (1) and (2) are valid only for the higher harmonic components of the zero sequence current and voltage in the frequency range up to $1.5-2 \mathrm{kHz}$.

Based on relations (1) and (2), it is possible to perform multifrequency adaptive current protection, which reacts in networks with an isolated neutral to the sum of the fundamental and higher harmonic components up to 1.5$2 \mathrm{kHz}$, in compensated networks only to the sum of higher harmonic components [11].

The structural and functional diagram of the universal multifrequency adaptive current protection is shown in Fig. 1.

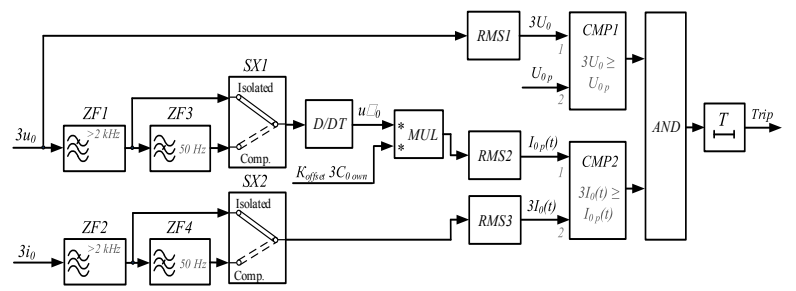

Fig. 1. Structural and functional diagram of universal multifrequency adaptive overcurrent protection against earth faults for compensated and uncompensated $6-10 \mathrm{kV}$ networks 
In Fig. 1: ZF1, ZF2 - digital low-pass filters suppressing components with a frequency higher than $1.5-2 \mathrm{kHz}$; ZF3, ZF4 - digital filters that suppress the component of the fundamental frequency; SX1, SX2 - neutral grounding mode switches; D/DT - differentiator; MUL multiplication; RMS1 - RMS3 - blocks for calculating root mean square value; CMP1, CMP2 - comparison of two values; $\mathrm{T}$ - time delay element. The RMS1 and CMP1 units form starting element of $3 U_{0}$, designed to trip protection against non-earth fault modes. The current value of the operating pickup current $I_{0 \mathrm{p}}(t)$ at input 2 of the comparison unit CMP2 is formed by multiplying in the MUL block the current value of the derivative $\mathrm{d} u_{0} / \mathrm{d} t$ at the output of the differentiator D/DT by the value of the protection setting parameter $K_{\text {offset }} 3 C_{0 \text { own }}$ and calculating the current rms value of the multiplication result of these values in block RMS2. The current value of the current $3 I_{0}(t)$ at the input 1 of the comparison unit CMP2 is formed in the RMS3 block.

The efficiency of the developed method of universal multifrequency adaptive current protection was investigated on simulation models of $6-10 \mathrm{kV}$ cable networks with different neutral grounding modes in the Matlab system. Figures 2 and 3 show, as an example, calculated oscillograms illustrating the protection operation for various types of internal and external earth faults (alternating arc earth fault, stable metallic fault and earth fault through a significant transition resistance of $1000 \mathrm{Ohm}$ ) in a $6 \mathrm{kV}$ cable network with an isolated neutral.
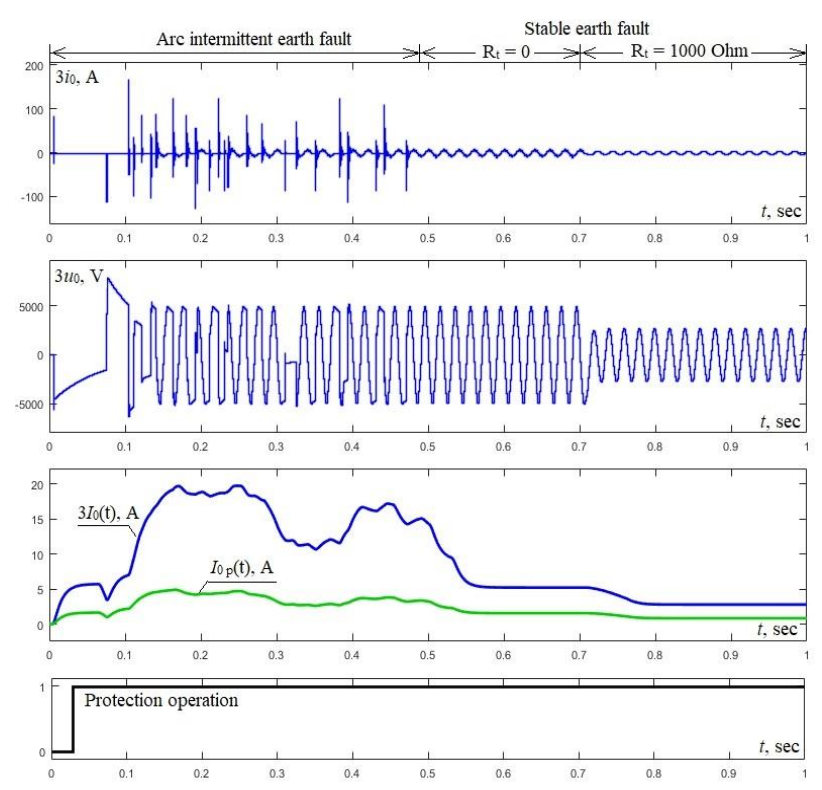

Fig. 2. Oscillograms illustrating the functioning of the adaptive overcurrent protection in a $6 \mathrm{kV}$ cable network with an isolated neutral for single-phase earth fault in the protection zone
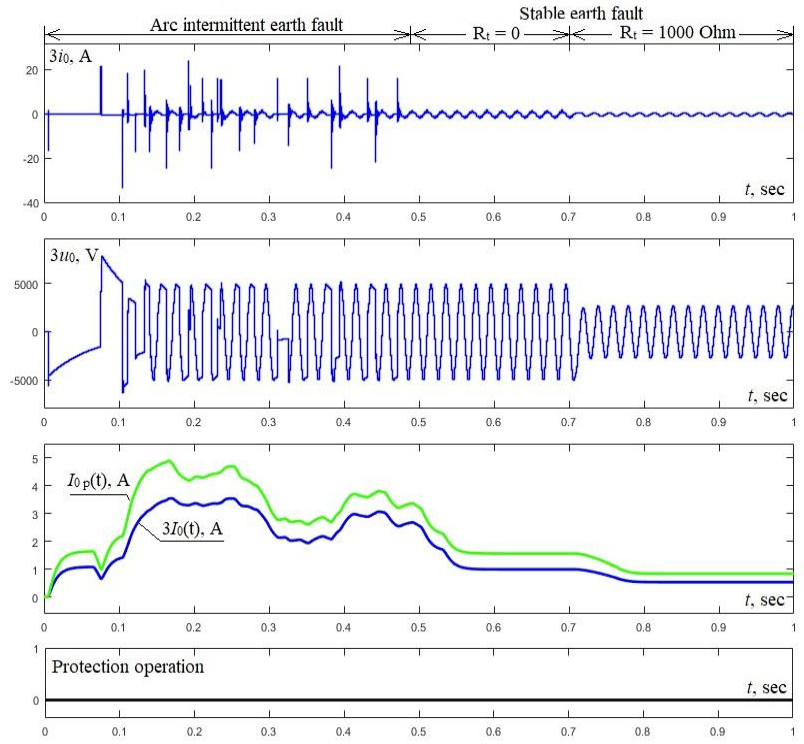

Fig. 3. Oscillograms illustrating the functioning of the adaptive current protection in a $6 \mathrm{kV}$ cable network with an isolated neutral for single-phase earth fault outside the protection zone

From the oscillograms shown in Fig. 2 and 3, it can be seen that the developed universal multifrequency adaptive overcurrent protection for 6-10 $\mathrm{kV}$ cable networks automatically adapts to changing operating conditions, providing the specified detuning and the required sensitivity both in the case of an intermittent arc and a stable earth fault.

The condition of applicability of the proposed protection in both compensated and uncompensated networks is determined by the ratio

$$
I_{\text {Cown }} \leq 1 /\left(1+K_{\text {offset }} K_{\text {sens.min }}\right)
$$

where $K_{\text {offset }}-$ coefficient taking into account the errors of the protection functioning; $K_{\text {sens.min }}-$ the minimum permissible sensitivity coefficient.

From (3) at $K_{\text {offset }}=1.5$ and $K_{\text {sens.min }}=1.5$, one can obtain $I_{\mathrm{C} \text { own }} \leq 0.3$. The condition $I_{\mathrm{C} \text { own }} \mathrm{x} \leq 0.3$ at power centers of $6-10 \mathrm{kV}$ cable networks is satisfied for $90 \%$ and more of connections, at distribution substations - for almost $100 \%$ of connections [5].

\section{Universal multifrequency directional and non-directional protection based on zero sequence capacitance}

From (1) and (2) for undamaged and damaged connections, we obtain, respectively

$$
\begin{gathered}
3 i_{0 \text { und }}(t) / u_{0}^{\prime}(t) \approx 3 C_{0 \text { und }}=3 C_{0 \text { own }} \\
3 i_{0 \text { dam }}(t) / u_{0}^{\prime}(t) \approx 3 C_{0 \text { dam }}=-3\left(C_{0 \Sigma}-C_{0 \text { own }}\right)
\end{gathered}
$$

From (4) and (5) it can be seen that in the frequency range up to $\sim 1.5-2 \mathrm{kHz}$ for undamaged connection (with external earth fault) the capacitance of the zero sequence loop of the protected connection $C_{0 \text { und }}$ is determined by the own capacitance of phase to earth $3 C_{0}$ own and is always positive. For a damaged connection, the 
capacitance $C_{0}$ dam of zero sequence loop is determined by the capacitance of phases to earth of the external network $3\left(C_{0 \Sigma}-3 C_{0 \text { own dam }}\right)$ and is always negative. Using the sign of the capacitance $C_{0}=3 i_{0}$ own $(t) / u_{0}^{\prime}(t)$ as an influencing quantity, it is possible to perform directional protection against single phase earth fault, the selectivity of which in the frequency range up to $\sim 1.5-$ $2 \mathrm{kHz}$ of the components of the input zero sequence current and voltage is provided as in steady-state and transient earth fault modes. To exclude the influence on the sign and magnitude of the measurement of angular errors, it was proposed in [12] to use for calculating $C_{0}$ instead of the ratio of instantaneous values of the compared quantities $3 i_{0}(t) / u_{0}^{\prime}(t)$, the ratio of the mutual correlation function of signals $3 i_{0}(t) / u_{0}^{\prime}(t)$ to the intrinsic correlation function of the signal $u_{0}^{\prime}(t)$ on a given observation time interval $T_{\mathrm{o}}$

$$
C_{0}=\left({ }_{0}{ }^{\text {To }} 3 i_{0}(t) u_{0}^{\prime}(t)\right) /\left({ }_{0}{ }^{\text {To }} u_{0}^{\prime}(t) u_{0}^{\prime}(t)\right)
$$

Ratio (6) gives the value of the capacitance of the zero sequence loop of the protected connection averaged over the time interval $T_{\mathrm{o}}$. With external faults, the ratio (6) is equal to the value of $C_{0}$ und $\approx 3 C_{0 \text { own }}$, and with internal faults $-C_{0 \text { dam }} \approx-3\left(C_{0 \Sigma}-C_{0}\right.$ own $)$.

Using the absolute measured value $\left|C_{0}\right|$ as the influencing variable, it is also possible to implement non-directional maximum earth fault protection. To ensure the selectivity of such protection malfunctions in case of external earth faults, the pickup setting should be selected from the condition

$$
3 C_{0 \mathrm{p}} \geq K_{\text {offset }}\left|C_{0 \text { und }}\right|=K_{\text {offset }} 3 C_{0 \text { own }}
$$

In compensated 6-10 kV cable networks, (4) and (5) are satisfied with any compensation mismatch only for the higher harmonic components of the current $3 i_{0 \mathrm{HH}}(t)$ and the derivative of the zero sequence voltage $u_{0 \mathrm{HH}}^{\prime}(t)$ in the frequency range up to $1.5-2 \mathrm{kHz}$. Taking this into account, relation (6) for compensated networks

$$
\left.\left.C_{0}={ }_{0} \int^{\mathrm{To}} 3 i_{0 \mathrm{HH}}(t) u_{0 \mathrm{HH}}^{\prime}(t)\right) /{ }_{0} \int^{\mathrm{To}} u_{0 \mathrm{HH}}^{\prime}(t) u_{0 \mathrm{HH}}^{\prime}(t)\right)
$$

From (6) and (8), it follows that for the application of the considered method in compensated networks in the scheme for the formation of the compared values, it is sufficient to provide filters that ensure the suppression of the component of the fundamental frequency in the supplied values $3 i_{0}(t)$ and $u_{0}^{\prime}(t)$. At the same time, the method of protection operation and the method of selecting its settings remain the same as in the network with an isolated neutral.

Since the conductivity of zero sequence loop of electrical network with an isolated neutral is almost purely capacitive, the protection based on the control of the capacitance $C_{0}$ can also conditionally be attributed to the class of admittance protection based on the control of conductivity. The advantages of the proposed protection is the independence of the measurement of the influencing value $C_{0}$ from the frequency of the supplied values, which, in contrast to traditional admittance protections, provides high selectivity and stability of functioning both in steady-state and in transient modes of single-phase earth faults.

In fig. 4 shows a scheme of the proposed universal earth fault protection based on the zero sequence capacitance.

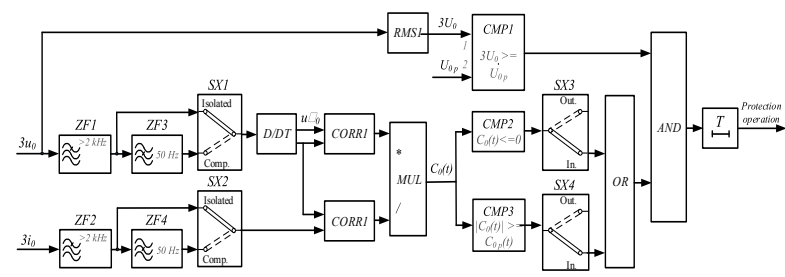

Fig. 4. Structural and functional scheme of universal earth fault protection based on zero sequence capacitance, where ZF1 ZF4, SX1, SX2, D/DT, RMS1, CMP1, T - the same as in Fig. 1; CORR1, CORR2 - the first and second correlators; MUL division unit; CMP2, CMP3 - comparators; SX3, SX4 switches for input and output of directional and non-directional protection

The first correlator CORR1 is designed to calculate the cross-correlation function of the current $3 i_{0}$ and the voltage derivative $u_{0}^{\prime}$, the second correlator CORR2 - to calculate the eigencorrelation function of $u_{0}^{\prime}$. The comparator CMP2 determines the sign of the value $C_{0}(t)$, the negative value of which corresponds to a earth fault on the protected connection, i.e. implements the function of directional protection. The comparator CMP3 compares the absolute value of $C_{0}$ with the pickup value $C_{0 \mathrm{p}}$ calculated according to (7), due to which the function of non-directional protection is realized.

The oscillograms shown in Fig. 5 and Fig. 6, illustrate the protection operation for internal and external earth faults (alternating arc earth fault, stable metallic fault and earth fault through a significant transition resistance of $1000 \mathrm{Ohm}$ ) in a $6 \mathrm{kV}$ cable network with an isolated neutral.

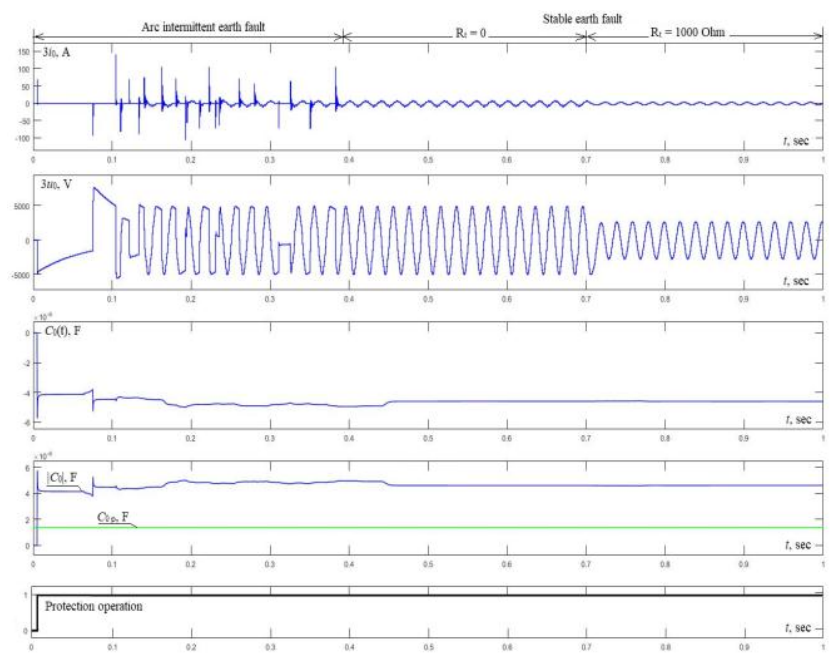

Fig. 5. Oscillograms illustrating the operation of universal protection based on zero sequence capacitance in a $6 \mathrm{kV}$ cable network with isolated neutral for earth fault in the protection zone 


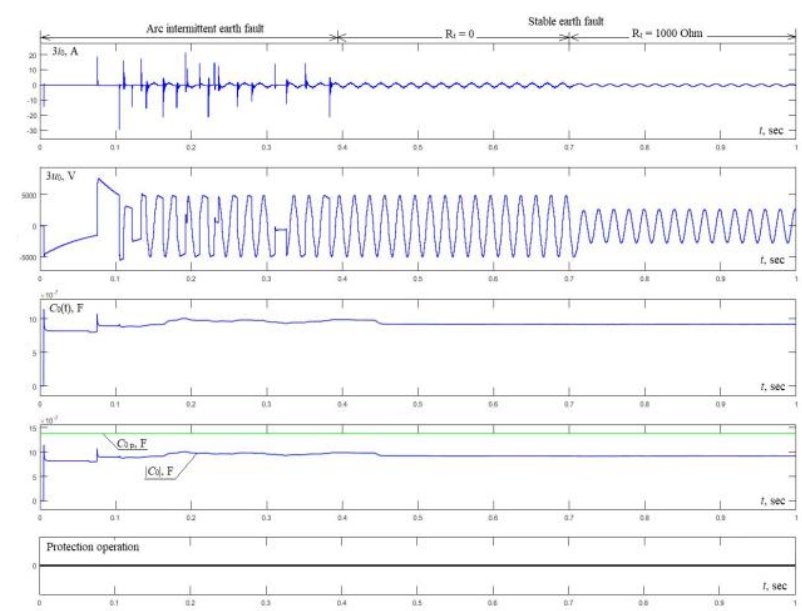

Fig. 6. Oscillograms illustrating the operation of universal protection based on zero sequence capacitance in a $6 \mathrm{kV}$ cable network with isolated neutral for earth fault outside the protection zone

\section{CONCLUSION}

A new approach has been proposed that provides universal technical solutions in terms of protection and signaling of single-phase earth faults, providing the possibility of their application both in compensated and uncompensated 6-10 $\mathrm{kV}$ cable networks. The advantages of the developed protections are also the independence from the neutral grounding mode of the setting selection procedure, which greatly simplifies the design and exploitation.

\section{References}

1. F.A.Likhachev, Zamykaniya na zemlyu $v$ setyah $s$ izolirovannoj nejtral'yu is kompensaciej emkostnyh tokov [Earth faults in networks with isolated neutral and capacitive current compensation], Energiya (1971)

2. V.A. Shuin, A.V. Gusenkov, Zashchity ot zamykanij na zemlyu $v$ elektricheskih setyah 6-10 kV [Protection against earth faults in electrical networks of 6-10 kV], Energetik (2001)

3. M.A. Shabad, Raschety relejnoj zashchity $i$ avtomatiki raspredelitel'nyh setej [Calculations of relay protection and automation of distribution networks], PEIPK (2003)

4. V.M. Kiskachi, Yu.G. Nazarov, Signalizaciya odnofaznyh zamykanij na zemlyu $v$ kompensirovannyh kabel'nyh setyah 6-10 $\mathrm{kV}$ [Signaling of single-phase earth faults in compensated cable networks 6-10 kV], Proceedings of VNIIE, Gosenergoizdat, 16 (1963), pp. 219-251

5. V.A. Shuin, V.A. Martynov, E.S. Shagurina, T.Yu. Shadrikova, Maksimal'nye tokovye zashchity ot zamykanij na zemlyu na osnove vysshih garmonik dlya kompensirovannyh kabel'nyh setej 6-10 kV [Maximum current protection against earth faults based on higher harmonics for compensated cable networks 6-10 kV], Electrical Engineering, 1 (2018), pp. 62-72
6. A.I. Shalin, Zamykaniya na zemlyu $v$ setyah 6-35 $k V$. Napravlennye zashchity. Osobennosti primeneniya [Earth faults in $6-35 \mathrm{kV}$ networks. Directional protection. Application features], Novosti elektrotekhniki, 6 (36) (2005) [Electronic resource].

URL: http://news.elteh.ru/arh/2005/36/09.php (date of access: 09/13/2020).

7. A.I. Shalin Zamykaniya na zemlyu v setyah 6-35 kV. Napravlennye zashchity. Vliyanie elektricheskoj dugi na napravlennye zashchity [Earth faults in 6$35 \mathrm{kV}$ networks. Directional protection. The influence of an electric arc on directional protection], News of ElectroTechnics, 1 (37) (2006) [Electronic resource]. URL: http://news.elteh.ru/arh/2006/37/06.php (date of access: 09/13/2020)

8. P. Olshovets, Admitansnye zashchity - effektivnoe sredstvo ohrany setej $S N$ ot zamykanij na zemlyu [Admittance protection - an effective means of protecting MV networks from ground faults], Relejnaya zashchita i avtomatizaciya, CHeboksary, 3 (28), (2017), pp. 56-59

9. I.N. Popov, V.F. Lachugin, G.V. Sokolova, Relejnaya zashchita, osnovannaya na kontrole perekhodnyh processov [Relay protection based on transient control], Energoatomizdat (1986)

10. A. Wahlroos, J. Altonen, Multifrequency admittance protection, Wiadomości Elektrotechniczne, 12 (2016)

11. V.A. Shuin, T.Yu. Shadikova, O.A. Dobryagina, E.S. Shagurina, S.N. Pashkovsky, patent of RF No. 2629375 H02H 3/16. Device for adaptive protection against single-phase earth faults in networks with isolated neutral and with compensation of capacitive currents, Bul. No. 25 $(08 / 29 / 2017)$

12. V.A.Shuin, Shadikova T.Yu., Dobryagina O.A., Shagurina E.S. RF patent $2688210 \mathrm{H} 02 \mathrm{H} \mathrm{3/16.}$ Protection device against single-phase earth faults in networks with isolated neutral and with compensation of capacitive currents, Bul. No. 15 $(05 / 21 / 2019)$

13. T.Yu. Shadrikova Razrabotka printsipov vypolneniya kompleksnoy mnogofunktsional'noy zashchity ot odnofaznykh zamykaniy na zemlyu kabel'nykh setey 6-10 kV [Development of principles for the implementation of a comprehensive multi-functional protection against single-phase earth faults of $6-10 \mathrm{kV}$ cable networks], PHD Thesis, Ivanovo, ISPEU, (2016) 